\section{Cureus}

\title{
Aortic Rupture During Surgical Management of Tubercular Spondylodiscitis
}

Phani Krishna Kartik Yelamarthy Dr ${ }^{1}$, Rajat Mahajan ${ }^{2}$, Tarush Rustagi ${ }^{3}$, Vikas Tandon ${ }^{4}$, Gururaj Sangondimath ${ }^{4}$, Harvinder Singh Chhabra ${ }^{5}$

1. Spine Surgery, Udai Omni Hospital, HYDERABAD, IND 2. Department of Spine Surgery, Indian Spinal Injuries Center, Noida, IND 3. Department of Spine Surgery, Indian Spinal Injuries Center, New Delhi, IND 4. Spine Surgery, Indian Spinal Injuries Center, New Delhi 5. Spine Surgery, Indian Spinal Injuries Center, New Delhi, NEW DELHI, IND

$\square$ Corresponding author: Phani Krishna Kartik Yelamarthy Dr, dryelamarthykarthik@gmail.com Disclosures can be found in Additional Information at the end of the article

\section{Abstract}

Aortic rupture is a rare but possible complication during spine surgery. It may manifest as severe intraoperative hemorrhage or present in a delayed manner after the formation of an aneurysm or an arteriovenous fistula. Though it is commonly encountered during anterior surgeries involving the surgical field close to the thoracic or abdominal aorta, it can also occur during a posterior surgery. Aortic injury could be associated with surgeries ranging from the commonly performed pedicle screw instrumentation to a complex three-column osteotomy. It can also occur, as in the reported case, while performing complex procedures in the presence of a pre-existing aneurysm or aortic adhesions due to coexisting infectious or inflammatory pathologies. The treatment options for such aortic ruptures range from open repair to endovascular stenting techniques. We discuss a case of an aortic rupture that occurred during a posterior vertebral column resection (PVCR) procedure performed on a 58-year-old female with spastic paraparesis secondary to tuberculous spondylodiscitis and the lessons learnt.

Categories: Infectious Disease, Neurosurgery, Orthopedics

Keywords: aortic rupture, complication, spine surgery, tubercular spondylodiscitis, pvcr

\section{Introduction}

Aortic rupture during a spine surgery is a known yet disastrous complication. It can be fatal and lead to the death of a patient on the operative table. It can occur due to pre-existing aortic aneurysms or aortic adhesions due to coexisting infectious or inflammatory pathologies, during anterior surgery while working around big vessels and rarely during posterior spinal surgery. The incidence depends on the anatomical region, surgical approach, primary pathology, implant-related issues, and the surgical expertise [1]. Injury to the aorta usually presents as immediate intraoperative hemorrhage, or it can present as a late manifestation due to the formation of an aneurysm or arteriovenous fistula [2]. We describe here a case of aortic injury during a posterior vertebral column resection (PVCR) procedure for tubercular thoracolumbar kyphotic deformity.

\section{Case Presentation}

\section{History}

A 58-year-old female presented with a gradually progressive, painful kyphotic deformity of the mid back of five months duration associated with progressive spastic paraparesis, with onset 


\section{Cureus}

two weeks before presenting to our clinic. On examination there was a tender gibbus deformity in the thoracolumbar junction with spastic paraparesis and exaggerated deep tendon reflexes. Her hematological parameters showed leukocytosis (14,000 cells/cubic millimeter) with an elevated erythrocytic sedimentation rate $(70 \mathrm{~mm} / \mathrm{hr})$. X-rays showed a focal kyphotic deformity at the thoracolumbar junction. Magnetic resonance imaging (MRI) was suggestive of spondylodiscitis at T12-L1 with epidural soft tissue components (Figure 1), likely secondary to a tubercular infective pathology.

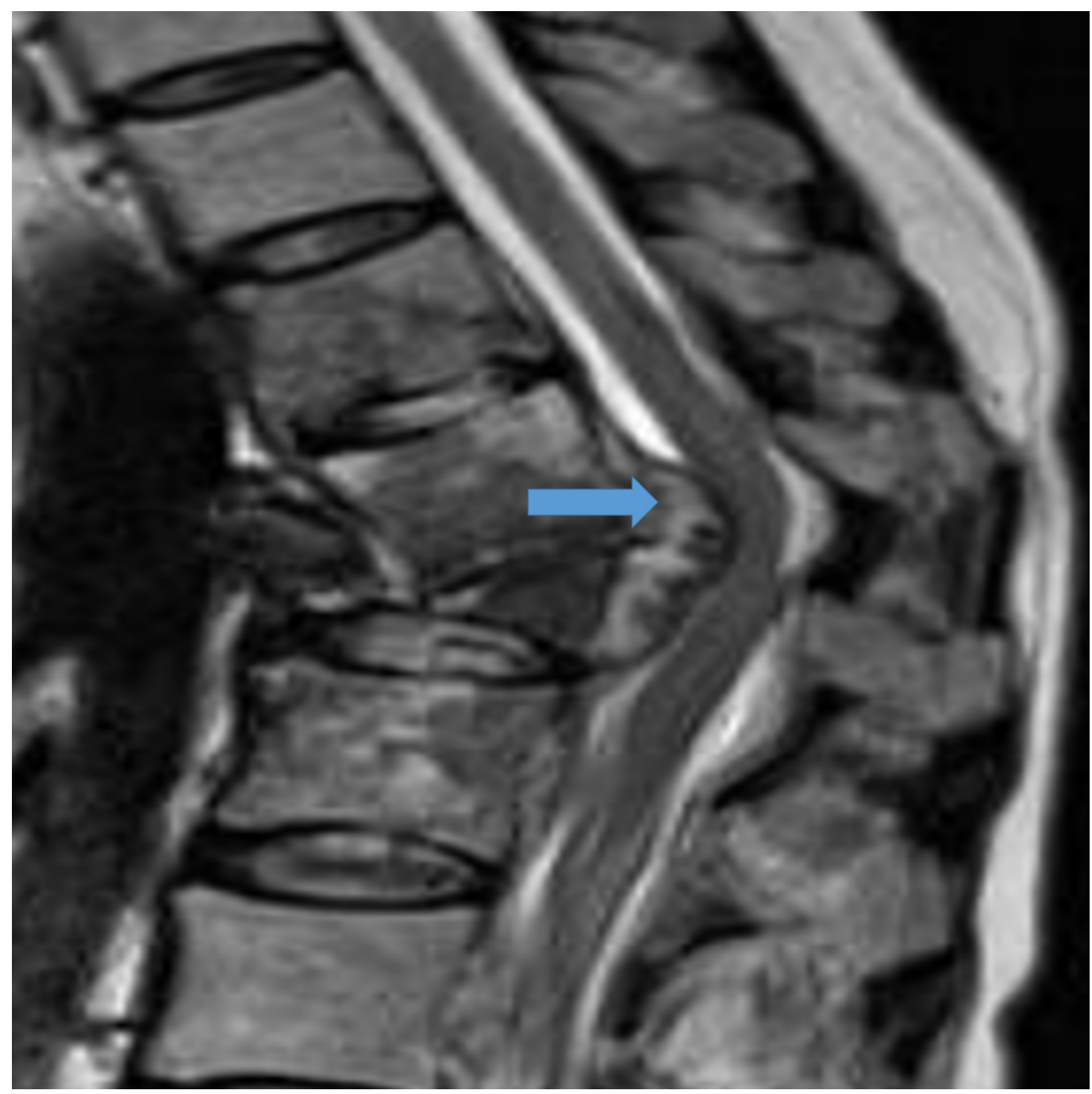

FIGURE 1: T2 MR sagittal image showing angular kyphosis at D12-L1 with epidural soft tissue component (block arrow) and accompanying cord compression.

MR - magnetic resonance

\section{Surgery and postoperative course}

Surgical planning was done to perform a PVCR of T12 and L1. After the surgical exposure, pedicle screws were inserted followed by a wide laminectomy of T11-L2, and a temporary rod was placed on the right side. This was followed by removal of the facets and pedicles of T12 and L1. At this time, vertebral body resection was started. During removal of the anterior part of the body, torrential arterial bleeding was encountered while removing one of the sequestered 
vertebral bone fragments. The anesthesia team was alerted of a probable aortic injury. The wound was packed, the rod was placed on the other side, rapid closure was done, and the vascular team was called in. Hemodynamics was maintained with rapid infusion of blood products and ionotropic support. In the right lateral position, a thoracoabdominal anterior approach was performed and the site of injury was identified. The aorta was found adhered to the surrounding structures. The source of bleeding was traced to the aorta where a $4 * 4 \mathrm{~mm}$ circumscribed irregular defect with friable inverted margins was identified. The defect was far posterolateral and was not freely accessible. After a couple of failed attempts due to difficult accessibility and friable margins, the vascular surgeon was able to pass a couple of sutures sealing the defect. There was no further active bleeding. Surgical procedure was then abandoned as the expected blood loss was around $4000 \mathrm{cc}$. The plan was for the vascular surgeon to do a semi-elective stenting procedure the next day to reinforce the repair. The patient was shifted to the intensive care unit but she expired the next day.

\section{Discussion}

Injury to thoracic or abdominal aorta has been reported to occur following spinal surgical procedures because of surgical armamentarium or pathologies distorting the normal anatomy of the aorta. Aortic injury has been reported during surgical exposure, insertion of pedicle screws, vertebroplasty, lumbar discectomy, lumbar interbody fusions, and during three-column osteotomies [3-6].

Spinal pathologies such as infections and inflammatory diseases result in adhesions of the aorta to its vicinity thus reducing the mobility and making them more prone to rupture spontaneously or iatrogenically or after minor trauma, especially if there is a pre-existing aneurysm [7]. Malposition of pedicle screws, even though under-reported, can be associated with aortic injury [5].

Our case was a post-infectious kyphotic deformity with spastic paraparesis of five month duration. The treatment of infectious spinal deformity has undergone a radical change during the last two decades. Earlier surgeons performed an anterior approach for most cases of spondylodiscitis associated with neurological deficit and implants were seldom used [8]. With the advent of pedicle screws, the posterior approach has gained popularity allowing deformity correction and anterior column reconstruction [9]. In order to address the deformity and perform adequate decompression, we opted for a single stage PVCR. On retrospective review of the images, we identified that one of the bone fragments was possibly stuck to the aorta (Figures $2 a-2 b)$. 


\section{Cureus}

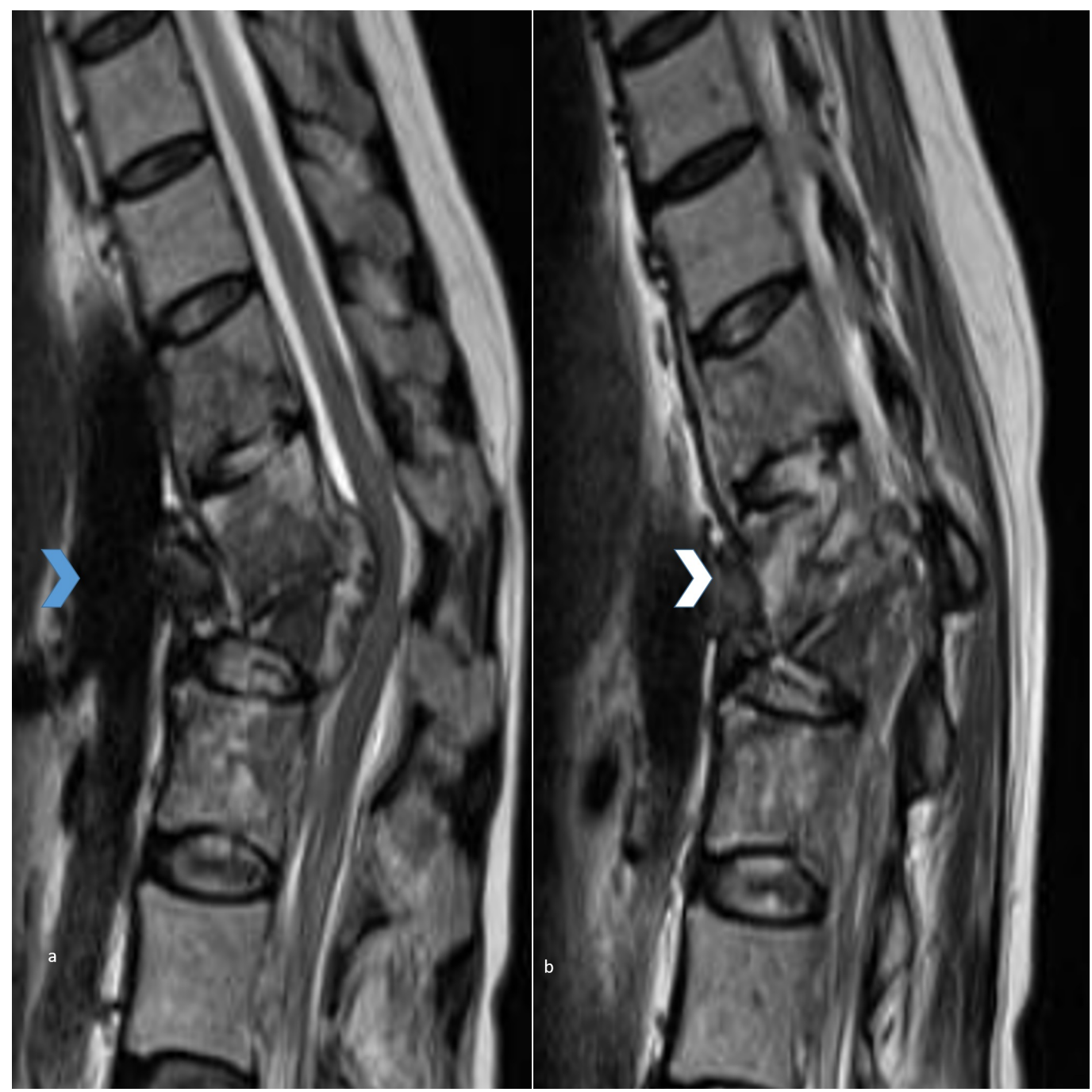

FIGURE 2: Figures $2 \mathrm{a}$ and $2 \mathrm{~b}$ showing midsagittal and parasagittal T2 MR sequences showing a sequestered fragment adherent to the aorta (aorta and the sequestered fragment are marked by blue and white bold arrows, respectively).

MR - magnetic resonance

During corpectomy, when this fragment was being fished out, there was a rupture of the aortic wall. Though we managed to repair the injured area of aorta, the patient succumbed on the next day due to complications of blood loss and disseminated intravascular coagulation (DIC) due to massive blood transfusion.

Spinal infections have been reported to be associated with spontaneous aortic rupture with or without associated aneurysmal formation [7]. Cage migration has been most commonly associated with vascular injury following three-column osteotomies [10, 6]. However, there are no previous reports of aortic injury during a three-column osteotomy for spondylodiscitis. We report a case of aortic injury following adhesions secondary to infectious spondylodiscitis, which turned to be of tubercular etiology (Tb PCR positive). MRI helps to identify aneurysmal formation, proximity of great vessels to the vertebral body, and to assess if any bony or soft 
tissue fragment is abutting the great vessels. Our case had no associated aneurysm formation, but in retrospect, we identified a bony fragment adhered to the aorta. Our case highlights the importance of critically evaluating the MRI, being cognizant of this catastrophic complication associated with tubercular spondylodiscitis. We feel that careful preoperative observation and further evaluation with arteriography may have made us more careful in performing corpectomy by leaving the possibly adhered fragment in situ.

\section{Conclusions}

Aortic rupture while performing a PVCR for spondylodiscitis has not been described before. Doing PVCR in spondylodiscitis can be a problem since long standing infection can be associated with the adherence of great vessels to the vertebral body. Our case highlights the significance of carefully evaluating the surrounding structures on the MRI preoperatively to look for adherent fragments to the aorta and leaving such fragments in situ during surgical resection to prevent surgical catastrophes.

\section{Additional Information}

\section{Disclosures}

Human subjects: Consent was obtained by all participants in this study. Conflicts of interest: In compliance with the ICMJE uniform disclosure form, all authors declare the following:

Payment/services info: All authors have declared that no financial support was received from any organization for the submitted work. Financial relationships: All authors have declared that they have no financial relationships at present or within the previous three years with any organizations that might have an interest in the submitted work. Other relationships: All authors have declared that there are no other relationships or activities that could appear to have influenced the submitted work.

\section{References}

1. Inamasu J, Guiot BH: Vascular injury and complication in neurosurgical spine surgery. Acta Neurochir. 2006, 148:375-386. 10.1007/s00701-005-0669-1

2. Reilly EF, Weger NS, Stawicki SP: Vascular injury during spinal surgery. Int J Acad Med. 2017, 3:39-43. 10.4103/IJAM.IJAM_97_16

3. Puri AS, Colen RR, Reddy AS, et al.: Lumbar artery pseudoaneurysm after percutaneous vertebroplasty: a unique vascular complication. J Neurosurg Spine. 2011, 14:296-299. 10.3171/2010.10.SPINE1082

4. Bae HJ, Cho TG, Kim CH, et al.: Aortic injury during transforaminal lumbar interbody fusion . Korean J Spine. 2017, 14:118-120. 10.14245/kjs.2017.14.3.118

5. Smythe WR, Carpenter JP: Upper abdominal aortic injury during spinal surgery . J Vasc Surg. 1997, 25:774-777. 10.1016/S0741-5214(97)70310-0

6. Higashino K, Katoh S, Sairyo K, et al.: Pseudoaneurysm of the thoracoabdominal aorta caused by a severe migration of an anterior spinal device. Spine J. 2008, 8:696-699. 10.1016/j.spinee.2007.03.007

7. Posacioglu H, Islamoglu F, Apaydin AZ, et al.: Rupture of a nonaneurysmal abdominal aorta due to spondylitis. Tex Heart Inst J. 2009, 36:65-68.

8. Langenskiold BA, Riska EB: Pott's paraplegia treated by anterolateral decompression in the thoracic and lumbar spine. A report of twenty-seven cases. Acta orthop Scandinav. 1967, 38:181-192. 10.3109/17453676708989632

9. McCormick J, Aebi M, Toby D, Arlet V: Pedicle screw instrumentation and spinal deformities: have we gone too far?. Eur Spine J. 2013, 22:216-224. 10.1007/s00586-012-2300-5

10. Jendrisak MD: Spontaneous abdominal aortic rupture from erosion by a lumbar spine fixation device: a case report. Surgery. 1986, 99:631-633. 